PLANEJAMENTO DO PRECO DE VENDA ${ }^{1}$

Roberto Vatan dos Santos

Professor do Departamento de Contabilidade da FEA/USP

Doutorando e Mestre em Controladoria e Contabilidade pela FEA/USP

\author{
Gestão de Preço de Venda é um conjunto \\ de atividades que conduzem o processo \\ decisório de preços e sua administração \\ na direção do objetivos da empresa.
}

\title{
INTRODUCÃO
}

A formação do preço de venda dos produtos e serviços nas empresas constitui-se numa estratégia competitiva de grande relevância para as organizações. A importância é ressaltada à medida que estas convivem com as imposições do mercado dos custos, do governo, da concorrência, e da disponibilidade financeira do consumidor. Salientando-se o fato de o atual ambiente situacional está caracterizado pela alta competitividade e em constante mudança tecnológica, as interações das empresas com o meio-ambiente devem ser coordenadas e integradas visando atingir sua missão, e conseqüentemente, a continuidade em longo prazo, a qual por sua vez, depende de seus resultados econômicos.

Através da otimização da relação preço/custo/volume é que a empresa pode: (1) obter um fluxo de lucros contínuo a longo prazo, permitindo a otimização no uso da capacidade instalada; e (2) garantir um retorno satisfatório sobre os capitais investidos no negócio.

O processo de decisão de preço envolve a coleta, ordenação e avaliação de diferentes variáveis complexas e interligadas que podem ser melhor entendidas e equacionadas através de um modelo de decisão empresarial, a ser utilizado como instrumento da gestão. O objeto principal de investigação deste estudo concentra-se na formulação de um modelo conceitual de decisão de preço de venda, reconhecendo as limitações de aplicabilidade e contribuições das abordagens existentes, que são: a) a teoria econômica; b) os custos; e c) o marketing.

O modelo proposto é apresentado sob um novo enfoque para o target price ou "preço-alvo", enfatizando a utilização do "Preço-Alvo de Mercado" e do "Preço-Alvo de Contribuição, e está estruturado sistemicamente para formulação, análise, mensuração econômica e avaliação das conseqüências resultantes de alternativas de preços, de forma a otimizar esta decisão e atender aos objetivos dos decisores de preço. É o mais genérico e flexível possível, permitindo sua adaptação à diversas estruturas organizacionais existentes, independente da existência ou não de áreas funcionais responsáveis diretamente pelo preço, embora reconheça-se que. para uma eficaz gestão de preços. recomenda-se a existência de responsáveis diretos. Também incorpora as vantagens da simulação e

\footnotetext{
${ }^{1}$ Trabalho premiado no III Congresso Brasileiro de Gestão Estratégica de Custos, promovido pela Universidade Federal do Paraná, realizado no período de 06 a 09 de outubro de 1996, Curitiba-PR
} 
possibilita a utilização de métodos probabilísticos no cálculo das variáveis, já que muitas delas são caracterizadas pelo risco e pela incerteza.

\section{Estruturacão Conceitual}

Este tópico demonstra a estrutura conceitual de um modelo de decisão de preço de venda, que pode auxiliar os gestores na geração, avaliação, mensuração econômica e análise de alternativas de preços e suas conseqüências propiciando a simulação do resultado econômico de cada curso de ação antes da decisão ser tomada: desta forma, possibilita otimizar o resultado da organização.

Um eficaz modelo de decisão de preço deve ser estruturado de tal forma, que possa incorporar os conceitos mais adequados originários da abordagem econômica, dos custos e do mercado. Desta maneira, da abordagem econômica, o modelo utiliza-se dos conceitos de curva de demanda, elasticidade-preço da demanda, estrutura e ambiente de mercado ao custo de oportunidade e resultado econômico.

Da abordagem dos custos, o modelo incorpora os conceitos: de custos fixos e variáveis, de custos diretos e indiretos, do método de custeio direto/variável, da análise da relação entre custovolume-lucro para multiprodutos, da avaliação dos ativos pelos custos correntes de reposição, do valor de realização liquido e pelo fluxo de caixa descontado, da mensuração dos custos dos insumos pelos custos correntes de reposição à vista, de custos-padrão e de custo de oportunidade sobre os investimentos realizados. Da abordagem de marketing o modelo utiliza-se dos conceitos de valor atribuído aos produtos. do ciclo de vida dos produtos, da segmentação de mercado, da análise da concorrência e das técnicas de mensuração e previsão de demanda.

\section{Estruturação Sistêmica}

Neste sentido, à luz da estruturação conceitual, um eficaz modelo de decisão de preço deve ser descrito de forma sistêmica; o objetivo deste tópico é descrever os passos necessários para operacionalização deste modelo. A Tabela 1 apresenta estas principais etapas conceituais e seu interrelacionamento mútuo. Algumas fases não precisam ser desenvolvidas seqüencialmente, mas sim simultaneamente, de forma a agilizar a aplicação do modelo e a obtenção das conseqüências advindas da simulação de cada alternativa de preço para um determinado produto. A Tabela 1 demonstra as grandes etapas do modelo proposto:

\section{Descricão das Etapas Operacionais do Modelo Target-Price ou "Preco-Alvo"}

1. avaliação estratégica das variáveis externas não-controláveis;

2. caracterização do ambiente de competição de mercado;

3. projeção da demanda de mercado e do produto;

4. projeção das vendas esperadas dos demais produtos da empresa;

5. identificação dos objetivos globais e funcionais da empresa e estabelecimento dos objetivos de preço;

6. identificação das políticas e diretrizes da empresa e estabelecimento das políticas e diretrizes de preço;

7. identificação das estratégias globais e funcionais da empresa e estabelecimento das estratégias de preço;

8. projeção da estrutura de custos e despesas da empresa;

9. apuração do capital investido no negócio e do respectivo custo de oportunidade;

10. aplicação do preço de simulação mais adequado;

11. obtenção da demonstração do resultado econômico;

12. Avaliação e adequação do preço referencial às condições de comercialização 
A seguir cada uma das fases é detalhada, explicitando-se os conceitos correspondentes:

\section{AVALIAÇÃO ESTRATÉGICA DAS VARIÁVEIS EXTERNAS NÃO- CONTROLÃVEIS}

As variáveis ambientais externas são todos os atores derivados do macroambiente, externos à empresa, que influenciam direta ou indiretamente a decisão de preços. Estas variáveis são, na verdade, $s$ diversos estados originados do ambiente da decisão, que não estão sob controle do decisor, mas que influenciam na escolha das alternativas de preços.

O macroambiente é formado pelas chamadas variáveis remotas, que influenciam o cenário econômico como um todo, tais como: tecnologia, mudanças políticas, legislação, estruturas econômicas, aspectos demográficos, aspectos culturais etc. Estes fatores, embora distantes, exercem influência indireta na empresa como, por exemplo, certos cataclismos (como enchentes, geadas, terremotos, etc.) em determinado pais produtor de alimentos, podem elevar os níveis de preço no mercado mundial devido à fada de oferta do produto.

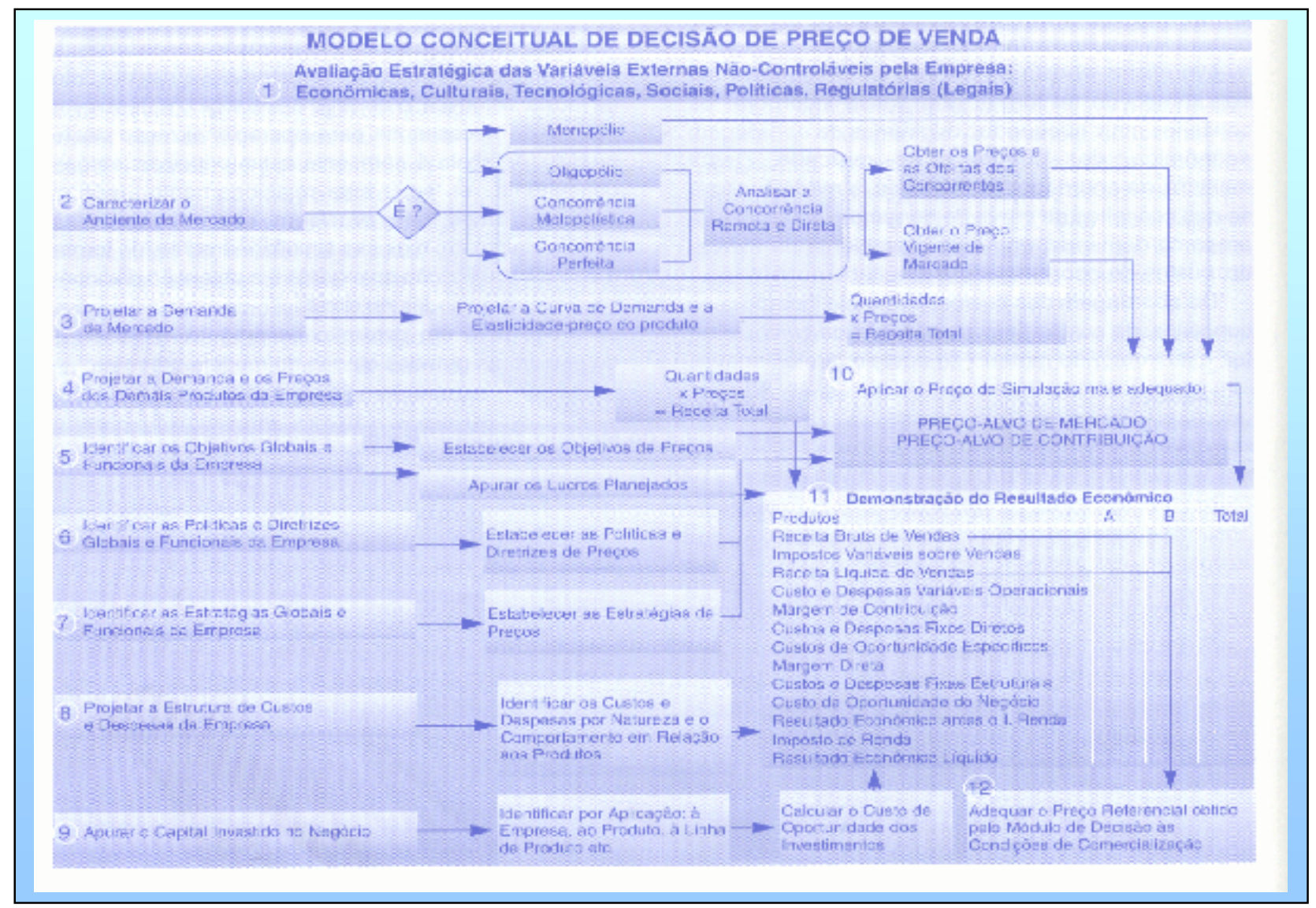

Caderno de Estudos, São Paulo, FIPECAFI, v.9, n.15, p.60 - 74, janeiro/junho 1997 
Esta avaliação, na verdade, corresponde a uma das fases do processo de planejamento estratégico, que possibilita ao gestor do negócio, e ao de preços, estabelecer o caminho a ser seguido pela organização, visando a otimizar a relação da em presa com o seu ambiente. Desta forma, o gestor de preços deve realizar permanente diagnóstico estratégico, através do monitoramento do meio-ambiente, buscando o aproveitamento das oportunidades de mercado, e percebendo as ameaças que possam criar condições desfavoráveis aos níveis de preços. Finalmente, cabe lembrar que estas variáveis são de tamanha amplitude, que influenciam, direta ou indiretamente, todas fases do modelo de decisão de preço. Podem alterar a estrutura do ambiente de competição de mercado, a demanda dos produtos ofertados pela empresa, a estrutura de custos da organização e seu custo de oportunidade sobre os investimentos realizados.

\section{CARACTERIZAÇÃO DO AMBIENTE DE COMPETIÇÃO DE MERCADO.}

Em primeiro lugar, a empresa deve identificar em qual ambiente econômico de mercado ela está operando. A expressão ambiente de mercado é utilizada para descrever as formas que umas empresas respondem às outras, quando elas tomam decisões de preço e de produto.

As principais estruturas de mercado, que geralmente se enquadram nos mercados atualmente existentes na sociedade são: a) concorrência perfeita: b) monopólio: c) oligopólio; e d) concorrência monopolística.

Nesta etapa. a empresa não deve deixar de analisar seus concorrentes diretos e potenciais. mapeando seus pontos fortes e fracos, objetivos, estratégias e padrões de reação. Aconselha-se, inclusive, a criacão de um sistema de inteligência sobre o concorrente, que seria um sistema formal de coleta de dados, interpretação e divulgação dos dados dos principais competidores de mercado.

Como produto desta fase haveria duas informações de extrema relevância:

a) os preços e as ofertas dos concorrentes diretos de mercado;

b) o preço vigente de mercado.

Obtidos estes dados, a organização poderá utiliza-los como preços de referência para a determinação de seu próprio preço através da etapa 10, e como preços de simulação do modelo de decisão de preço. Já para uma empresa monopolista, e que portanto determina o preço de oferta no mercado, a fase 10 do modelo servirá para obter o preço-alvo de contribuição, que será o preço mínimo que remunera seus investimentos, e permitirá o alcance de seus objetivos.

\section{PROJEÇÃO DA DEMANDA DE MERCADO E DO PRODUTO}

Dependendo da estrutura de mercado em que a empresa está operando cada preço ofertado resultará num nível diferente de quantidade demandada e, conseqüentemente, numa receita de vendas. O grau de elasticidade-preço da demanda, de um produto determinará um aumento ou diminuição na receita total gerada de sua venda pela empresa.

O principal produto desta fase será uma tabela de níveis de preços e quantidades. 
representando a curva de demanda, com a qual a empresa se defronta para o produto em questão, que será utilizada no módulo de simulação (etapa 10) do modelo de decisão de preço.

\section{PROJEÇÃO DAS VENDAS ESPERADAS DOS \\ DEMAIS PRODUTOS DA EMPRESA.}

Dentro do enfoque sistêmico as vendas e o preço de um produto especifico dependem dos níveis de vendas e preços dos demais produtos da empresa. Este inter-relacionamento é definido como sendo o 'mix', ou o composto de produtos praticado pela empresa, que no seu conjunto deve garantir o retorno satisfatório de seus investimentos. E necessário entender que os preços dos diversos produtos ofertados pela empresa não podem ser analisados isoladamente, pois os mesmos utilizamse de recursos comuns e de certa forma concorrem entre si.

O composto de produtos ou "mix" de vendas é definido na etapa de planejamento operacional do processo de gestão, em que são estudadas diferentes alternativas de quantidades, preços, prazos de recebimento, canais de distribuição. etc. e procedimentos operacionais que orientam as decisões de preço. Como produto desta fase, teria-se uma tabela com os diferentes produtos ofertados pela empresa com seus respectivos níveis de preços e quantidades previstas de vendas, que será utilizada no módulo de simulação (etapa 10) do modelo de decisão de preço.

\section{IDENTIFICAÇÃO DOS OBJETIVOS GLOBAIS E FUNCIONAIS DA EMPRESA E O ESTABELECIMENTO DOS OBJETIVOS DE PREÇO.}

Um eficaz modelo de decisão de preço deve à função- objetivo do decisor de preços, bem como garantir a continuidade da organização. A definição do objetivo de preço é condicionada pelos objetivos da empresa como um todo. O preço é uma das variáveis decisórias, portanto controlável, que deve servir a algum propósito.

Para uma decisão de preço ser eficaz, é necessária a definição clara e precisa de sua funçãoobjetivo, especificando-se a situação desejada dentro do ambiente de decisão. Pode-se complementar dizendo que, uma empresa estará no caminho certo, se para o produto em questão já tiver decidido seu mercado-alvo e seu posicionamento de mercado, bem como sua estratégia de marketing.

Acrescente-se que os objetivos da decisão de preço podem envolver horizontes de planejamento diferentes. Objetivos podem ser determinados para serem atingidos no curto, no médio e no longo prazo, dependendo do problema analisado. Pode-se inclusive, estabelecer sub-objetivos de preços para serem atingidos no curto prazo que, no seu conjunto, permitam o alcance de um ou vários objetivos de longo prazo.

Desta forma, a empresa pode ter objetivos principais, a serem perseguidos com maior ênfase, e objetivos colaterais, que serão uma série de metas que a organização procura atingir conjuntamente com os principais. Resumindo-se os objetivos de preço a serem perseguidos. isolados ou conjuntamente, por uma empresa, em três grandes grupos, tem-se:

a) objetivos orientados para o lucro;

b) objetivos orientados para as vendas:

c) objetivos orientados para a manutenção status quo. 
Portanto, como resultado desta fase existiriam dois produtos principais:

a) declaração dos objetivos de preço do produto em questão;

b) estabelecimento do lucro necessário, desejado ou planejado para atingimento dos objetivos globais da empresa.

Recomenda-se uma declaração formal e clara dos objetivos de preço do produto em questão, como por exemplo: "O objetivo do preço do produto "X" é permitir uma penetração acentuada no mercado, de forma a propiciar o crescimento das vendas, o aumento da participação no mercado, a redução dos custos de produção e logística e a criação de uma barreira de entrada a novos concorrentes.'

O estabelecimento do lucro necessário, desejado ou planejado, para atingir os objetivos globais da empresa corresponde ao atendimento das premissas de continuidade da organização e à existência de processos de planejamento e controle orçamentários integrados. Aconselha-se, inclusive, que seja expresso através de unidades monetárias, para um determinado período de tempo. Como por exemplo: "O lucro meta, que atende os objetivos globais da empresa, no período orçamentário de $19 \times 0$, é de $\$ 1.200 .000$ unidades monetárias, correspondentes de $\$ 100.000$ unidades monetárias por mês em média".

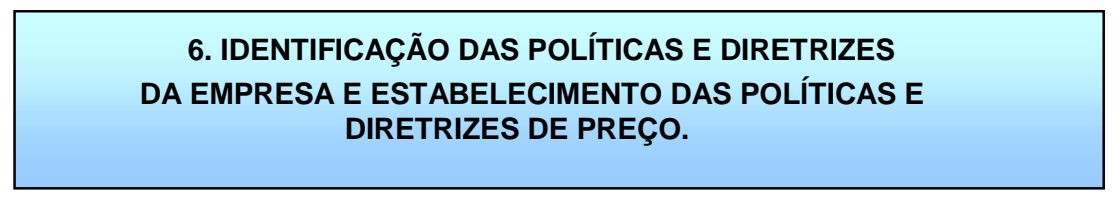

Políticas e diretrizes de preço são regras de decisão ou conduta adotadas pela empresa, que orientam o decisor na escolha da alternativa de preço em situações repetitivas. Estas devem ser congruentes com as políticas globais e funcionais da empresa, para um determinado produto ou linha de produtos e também permitir alcançar os objetivos e metas preestabelecidos. Exemplos de políticas seriam:

a) fixar preços de produtos de acordo com os preços médios de mercado;

b) os preços deverão se ajustar rapidamente às variações de preço dos concorrentes;

C) os preços deverão ser reajustados ou reavaliados quinzenalmente;

d) os revendedores devem seguir o preço determinado pelo fabricante;

e) deve-se realizar promoções de preço sazonais, etc.

As políticas podem ser agrupadas em três grandes grupos, conforme os objetivos globais, funcionais e de preços estabelecidos pela empresa. Estes seriam: a) políticas e diretrizes de preço visando a seleção de mercado; b) políticas e diretrizes de preço visando a penetração de mercado; e c) políticas e diretrizes de preço visando a discriminação de mercado.

As políticas e diretrizes funcionais, que mais influenciam a decisão de preço, geralmente, são as relativas à linha de produtos, canais de distribuição e promoção, que juntamente com o preço, constituem as variáveis decisórias do composto de marketing. No entanto, não se deve esquecer que outras áreas como Finanças, Produção, Logística, etc., através de suas políticas, podem influenciar na determinação do preço de um certo produto. Outro aspecto, também é possível especificá-las de acordo com o ambiente econômico de mercado no qual a empresa opera, e levando-se em consideração o estágio do ciclo de vida do produto. Como produto final desta fase, teria-se uma 
declaração formal e clara das políticas e diretrizes de preço a serem seguidas pelo gestor de preços. Como por exemplo: "Nossa empresa deve manter um preço abaixo dos preços médios do setor, ajustando-os rapidamente à qualquer variação de preço da concorrência. Poderão ser praticados descontos cumulativos por quantidades compradas, seguindo-se sempre a tabela de preços em vigor".

\section{IDENTIFICAÇÃO DAS ESTRATÉGIAS GLOBAIS E FUNCIONAIS DA EMPRESA E ESTABELECIMENTO DAS ESTRATÉGIAS DE PREÇO.}

Estratégias de preço representam afirmações abrangentes de como os preços serão utilizados para atingir os objetivos globais e funcionais da empresa. São guias de orientação das decisões de preço e coordenação das atividades relacionadas para um determinado produto, ou linha de produto, em um certo período de tempo mais ou menos longo, sendo também flexível e adaptável às alterações das condições ambientais. Exemplos de estratégias de preço, seriam:

a) fixar um preço mínimo, que apenas cubra os custos;

b) estabelecer um preço elevado de forma a diferenciar o produto;

c) estabelecer preços baixos, de forma a penetrar em novos segmentos de mercado;

d) oferecer preços por pacotes de produtos e serviços, etc.

$\mathrm{Na}$ realidade, as estratégias de preço não podem ser estabelecidas isoladamente, mas sim fazem parte de um conjunto de estratégias que compõem a estratégia global da companhia. Especificamente, a estratégia de preço é um componente da estratégia de marketing de uma empresa. A estratégia de marketing define os princípios amplos pelos quais a unidade de negócio espera realizar seus objetivos de marketing em um mercado-alvo. Portanto, como produto final desta fase, teria-se o estabelecimento formal das estratégias de preço para o produto em questão como por exemplo: "Nossa empresa adota para o produto $X$ ' um preço baixo em relação a: a) preço médio dos principais concorrentes diretos da região de venda; e b) aquilo que os clientes estão acostumados a pagar".

\section{PROJEÇÃO DA ESTRUTURA DE CUSTOS E DESPESAS DA EMPRESA.}

Esta fase é caracterizada pela identificação, acumulação e apropriação dos custos e despesas da empresa aos produtos objetos de decisão de preço de venda, incluindo-se também os impostos fixos ou variáveis incidentes sobre as atividades da empresa. Os dados obtidos nesta etapa serão utilizados na etapa 11, que tem como função à simulação do resultado econômico das diferentes alternativas de preço através da demonstração do resultado econômico. Certos custos e despesas são do negócio, ou seja, estruturais, periódicos e decorrentes da capacidade instalada, visando a manutenção de certo nível potencial de atividade pela entidade. E fundamental, nesta fase, serem identificados os Custos e Despesas Fixos e os Custos e Despesas Variáveis em relação ao produto objeto da decisão de preço de venda.

Outro ponto relevante é identificar os custos diretos e indiretos do produto. Estes, devem ser segundo: Custos Fixos Diretos, Custos Fixos Indiretos, Custos Variáveis Diretos e Custos Variáveis 
Indiretos, em relação ao produto. São acumulados através de um sistema de acumulação de custos, que se utilize do método de custeio direto/variável, que se caracteriza por apropriar aos produtos somente os seus respectivos custos variáveis: portanto não se admite a aplicação de rateios de custos fixos aos produtos objetos da decisão de preços. Desta forma, para que um custo seja apropriado ao custo do produto o mesmo deve ser variável, isto é, variar de acordo com a quantidade produzida.

Acrescenta-se também que os custos relevantes para apuração de preço de venda são os custos futuros de reposição à vista dos insumos produtivos sob o enfoque de custo-padrão planejados para a data de entrega dos produtos aos clientes. Estes são apurados através de um sistema de custeio a valores futuros pré- determinados. Como produto final desta etapa devem ser obtidos:

a) os custos e despesas variáveis operacionais unitários de cada produto fabricado pela empresa valorizados pelos seus custos futuros de reposição à vista sob o enfoque de custos-padrão:

b) os custos e despesas fixos diretos plenamente identificáveis (sem rateio) ou considerados específicos a determinados produtos:

c) os custos e despesas fixos estruturais decorrentes da operação do negócio e que são comuns a tocos os produtos:

d) os percentuais das despesas com impostos e suas respectivas bases de cálculo:

e) os impostos fixos incidentes sobre determinados produtos ou comuns ao negócio.

\section{APURAÇÃO DO CAPITAL INVESTIDO NO NEGOCIO E DO} RESPECTIVO CUSTO DE OPORTUNIDADE.

Sob o enfoque econômico, os investimentos realizados pelos donos da empresa necessitam ser remunerados, no mínimo, pelo custo de oportunidade das quantias investidas no negócio. Custos de oportunidade para os proprietários, correspondem à remuneração sacrificada pela utilização dos recursos na empresa ao invés de outra alternativa de investimento com equivalente risco e grau de satisfação.

Deve ser apurado o custo de oportunidade do negocio como um todo, tais como investimentos realizados em terrenos, edifícios, equipamentos, instalações, móveis, etc., que são comuns a todos os produtos da empresa, bem como os investimentos realizados em ativos que somente beneficiam certos produtos especificamente, como por exemplo: estoques exclusivos de materiais, maquinas e equipamentos delicados, etc.

Conceitualmente, as taxas ideais, para serem utilizadas no calculo do custo de oportunidade dos investimentos realizados, seriam o retorno exigido pela empresa ou o seu custo de capital. No entanto, em uma atitude conservadora, por razões operacionais e de disponibilidade de informações, diversos gestores de preços têm se utilizado das taxas médias de captação de recursos no mercado financeiro, ou das taxas de captação conseguidas pela empresa no mercado financeiro. Por outro lado, os investimentos realizados devem estar mensurados segundo critérios econômicos adequados, de tal forma que possam refletir a respectiva capacidade potencial de geração de benefícios ou serviços futuros.

Portanto, como produtos desta fase teria-se:

a) o custo de oportunidade de investimentos realizados especificamente para determinados produtos da empresa:

b) o custo de oportunidade de investimentos realizados para o negócio como um todo. 


\section{APLICAÇÃO DO PREÇO DE SIMULAÇÃO MAIS} ADEQUADO.

Nesta etapa. o gestor de preços deve escolher qual preço de venda utilizar para simular os resultados de cada alternativa de preço. Dependendo co ambiente econômico de mercado no qual a empresa esta inserida, tem à sua disposição duas possibilidades.

a) utilizar o preço-alvo de mercado ou market targeprice; ou contribuition target-price.

O preço-alvo de mercado deverá ser aplicado quando a empresa operar em ambientes de mercado caracterizados pelo oligopólio, ou pela concorrência monopolística e por uma elevada competição. A determinação deste preço-alvo está coerente com as abordagens contemporâneas e proativas de gestão de marketing e de mercado, em que a empresa: capta através de pesquisas de mercado as necessidades e desejos dos indivíduos: projeta um conceito de produto que as satisfaça: segmenta o mercado; define um mercado-alvo especifico. com uma qualidade e preço planejados de acordo com o valor percebido, estruturando sua estratégia de composto mercadológico: definindo assim seu posicionamento de mercado e estimando sua participação neste, através do volume que espera vender ao preço estabelecido.

Em produtos já existentes, o estabelecimento do preço-alvo de mercado dependerá do posicionamento atual da empresa no mesmo, como por exemplo: se a mesma é uma "líder de preços" ou "seguidora de preços", ou até se existe um acordo formal ou informal de preços em setores oligopolizados de mercado. Por outro lado, em ambientes de mercado caracterizados por uma intensa competição, o preço-alvo poderá ser o próprio preço vigente de mercado, cabendo ao gestor de preços aceitá-lo ou não, pois se fixar preços acima do que o mercado está disposto a pagar, poderá não obter volumes de vendas adequados ao seu nível de atividade.

O preço-alvo de contribuição deverá ser aplicado quando a empresa opera em ambientes de mercado caracterizados pelo monopólio, pela concorrência monopolistica e em situações em que a empresa tem alguma liberdade de fixar o preço como em ambientes de baixa competição.

Em produtos novos, o preço-alvo de contribuição é formado a partir da margem de contribuição desejada, necessária, definida ou objetivada pela empresa para um produto específico, para uma linha de produtos ou para a organização como um todo. Vale ressaltar que a margem de contribuição total a ser atingida é o somatório das margens de contribuição obtidas por todos os produtos vendidos pela entidade que, deduzida dos custos e despesas fixos totais, propiciará o resultado econômico definido como objetivo no plano de lucros da empresa. Em produtos já comercializados pela empresa, preço-alvo de contribuição dependerá da margem de contribuição atualmente obtida pela empresa e em cada produto, e dependem basicamente da combinação de três fatores:

a) do volume de vendas em unidades;

b) do preço unitário de venda;

c) do "mix" de venda dos produtos. 


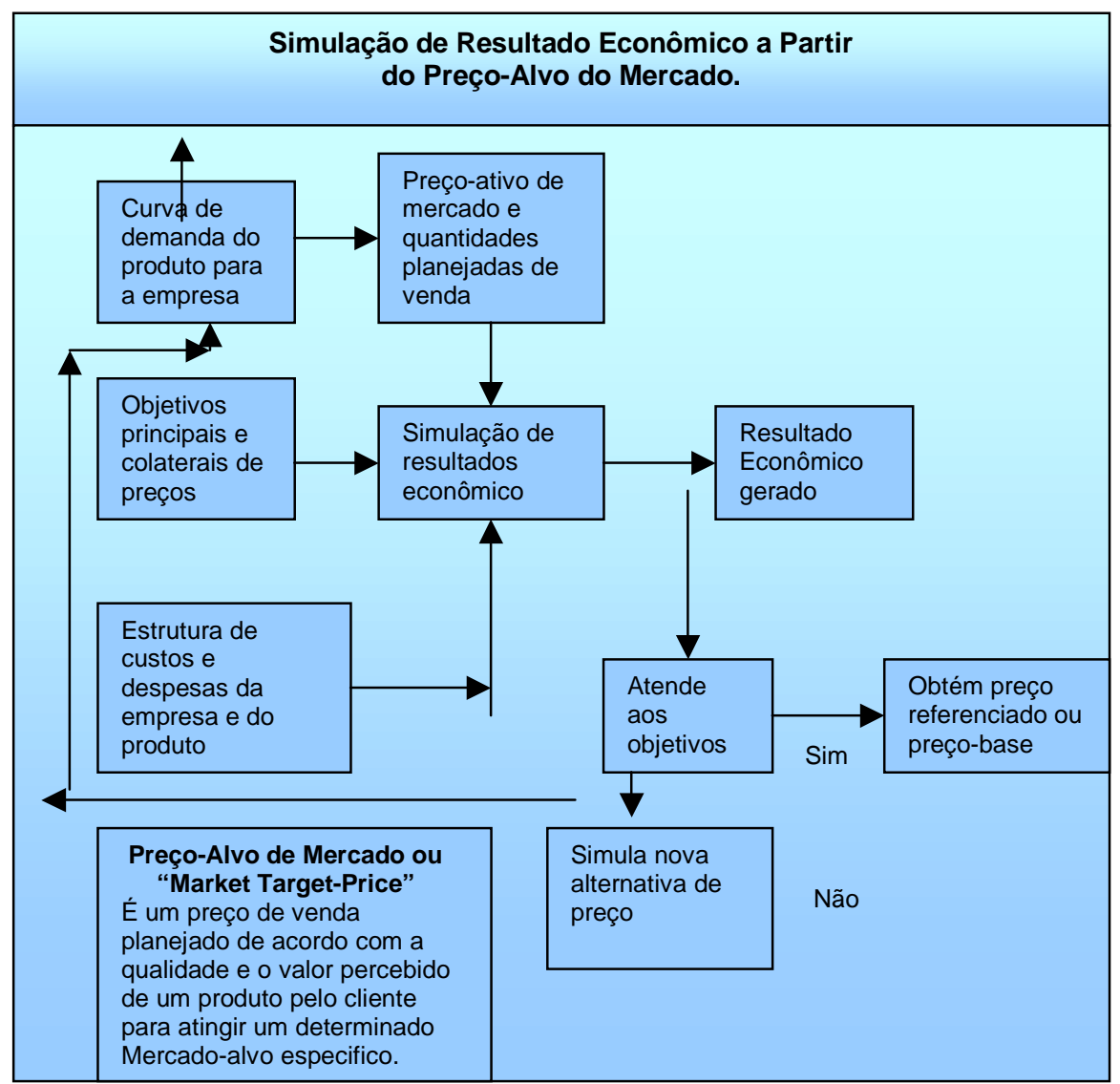

A cada nível de preço, haverá uma quantidade diferente demandada, segundo o modelo de mensuração de demanda da empresa, que possibilitará ao gestor de preços testar diferentes alternativas de preços de venda que otimizem seu resultado econômico.

\section{OBTENÇÃO DA DEMONSTRAÇÃO DO RESULTADO ECONOMICO}

O resultado econômico é conseguido através do processamento dos dados recebidos das etapas anteriores. Esta etapa, na verdade é o módulo de simulação do modelo de decisão de preço de venda, pois permite ao gestor de preços avaliar o impacto no resultado econômico das diversas alternativas de preço. Quando o gestor de preços utiliza-se do preço-alvo de mercado, ele consegue, através do módulo de simulação do resultado econômico, uma margem de contribuição gerada ou calculada, que ao ser somada com as demais margens geradas pelos outros produtos da empresa. deve obter um valor suficiente para cobrir os custos e despesas fixos diretamente relacionados aos produtos, os custos e despesas estruturais da empresa, os custos de oportunidade específicos e do negócio, o imposto de renda e ainda propiciar a lucro planejado.

Dentro de um processo iterativo, o decisor de preços pode ir testando diversas opções de volumes de venda e preços unitários de venda, conforme a curva de demanda do produto para a empresa, de modo obter a melhor combinação que atenda os seus objetivos principais e colaterais. A Figura 2 representa esta iteração tendo como parâmetro de decisão o resultado econômico gerado. 
Se o mesmo atender os objetivos de preços, então o gestor terá um preço-referencial ou preço-base que necessita ser adequado às condições de comercialização do produto (veja etapa 12 do modelo). Caso o resultado econômico gerado não for satisfatório, o gestor de preços poderá simular outras alternativas, ate encontrar aquela que he atenda, ou abandonar a venda do produto em questão.

A seguir são apresentados exemplos numéricos hipotéticos para uma empresa "Z" que fabrica e comercializa três produtos. A, B e X, e que necessita decidir qual o preço mais Custos adequado para a venda do produto " $X$ " a partir do preço-alvo de mercado para o próximo Custos período de um mês.

1) Projeção na curva na demanda do produto para a empresa:

\begin{tabular}{|c|c|c|c|}
\hline Preço de Venda & \multicolumn{2}{|c|}{ Quantidades } & Receita Bruta \\
\hline \multicolumn{4}{|l|}{ (Brutos) } \\
\hline 10 & \multicolumn{2}{|c|}{1.000} & 10.000 \\
\hline $15 \backslash$ & \multicolumn{2}{|c|}{900} & 13.500 \\
\hline 20 & \multicolumn{2}{|c|}{800} & 16.000 \\
\hline 25 & \multicolumn{2}{|c|}{700} & 17.500 \\
\hline \multicolumn{4}{|c|}{ Preço-alvo de mercado } \\
\hline Produtos & $\begin{array}{c}\text { Preços de venda } \\
\text { (brutos) }\end{array}$ & Quantidades & Receita Bruta de vendas \\
\hline A & 25 & 600 & 15.000 \\
\hline B & 30 & 800 & 24.000 \\
\hline
\end{tabular}

3) Resultado econômico liquido ob objetivado no período: $\$ 4.000$

4) Projeção da estrutura de custos e despesas da empresa:

\begin{tabular}{|l|r|r|r|r|}
\hline \multicolumn{2}{|c|}{ Produtos } & \multicolumn{1}{|c|}{ B } & X & TOTAL \\
\hline Custos Variáveis operacionais unitários & 12 & 15 & 7 & \\
Custos fixos diretos & 2.00 & - & - & 2.000 \\
Custos e despesas fixas e estruturais & - & - & - & 8.000 \\
Ativos específicos Ativos comuns & 15.000 & - & - & 15.000 \\
Taxa de custo de oportunidade (\% ao mês) & - & - & - & 200.000 \\
Custos de oportunidades específicos & $1 \%$ & $1 \%$ & $1 \%$ & $1 \%$ \\
Custos de oportunidade ao negócio & 150 & - & - & 150 \\
Impostos vaiáveis sobre venda; & - & - & - & 2000 \\
Alíquota do imposto de renda. & $10 \%$ & $10 \%$ & $10 \%$ & $10 \%$ \\
& - & - & - & $40 \%$ \\
\hline
\end{tabular}

Neste caso, o preço-alvo de mercado de $\$ 15$ é plenamente aceitável, pois o resultado econômico, gerado nesta alternativa de preço, é superior ao lucro objetivado pela empresa para o período. Por outro lado, quando o gestor de preços utiliza-se do preço-alvo de contribuição, precisa de uma margem de contribuição objetivada, que representa a quantia que a empresa planejou ou tem necessidade para satisfazer seus objetivos principais e colaterais, que ao ser somada com as demais margens geradas pelos outros produtos da empresa, deve gerar um valor suficiente para cobrir os custos e despesas fixos diretamente relacionados aos produtos. os custos e despesas estruturais da empresa, os custos de oportunidade específicos e do negócio, o imposto de renda e 
propiciar o lucro planejado.

Esta margem de contribuição objetivada pode ser expressa por: a) um percentual sobre o preço de venda líquido (sem os impostos variáveis de vendas); b) um determinado valor unitário, quando a empresa tem pleno conhecimento da quantidade a ser vendida e fabricada.

E mais prático e operacional expressar esta margem na forma de percentuais, que podem seguir as seguintes regras de aplicação:

1) se o produto é novo, mas pertence a uma linha de produtos já existente, a empresa pode se utilizar do percentual médio da margem de contribuição, que está atualmente obtendo na linha de produtos ou na empresa como um todo;

2) se o produto é novo e pertence a uma linha de produtos inédita, então a empresa pode se utilizar do percentual médio da margem de contribuição, que está atualmente obtendo na empresa como um todo;

3) se o produto é regular e está sofrendo um processo de reavaliação de preços cara um novo canal de distribuição, ou devido às alterações na estrutura de custos, ou de mudanças no produto, etc. então a empresa pode se fazer uso do percentual médio que está atualmente obtendo no produto, ou em sua linha de produtos.

Dentro de um processo iterativo, o decisor de preços pode testar diversas opções de margens de contribuição, combinando-as com os volumes de venda estimados pela curva de demanda do produto para a empresa, nas diferentes alternativas de preços de venda, e conseguir a melhor combinação que atenda seus objetivos principais e colaterais. A Figura 3 representa esta iteração e tem como parâmetro de decisão o resultado econômico gerado. Se o mesmo atender os objetivos de preços, então o gestor terá um preço referencial ou preço-base, que necessita ser adequado às condições de comercialização do produto, objeto de estudo da etapa 12 do modelo. Caso o resultado econômico gerado não for satisfatório, pode-se simular outras alternativas de margens de contribuição, volumes de venda e preços unitários de venda, até encontrar aquela que lhe atenda ou então abandonar a venda do produto em questão. 


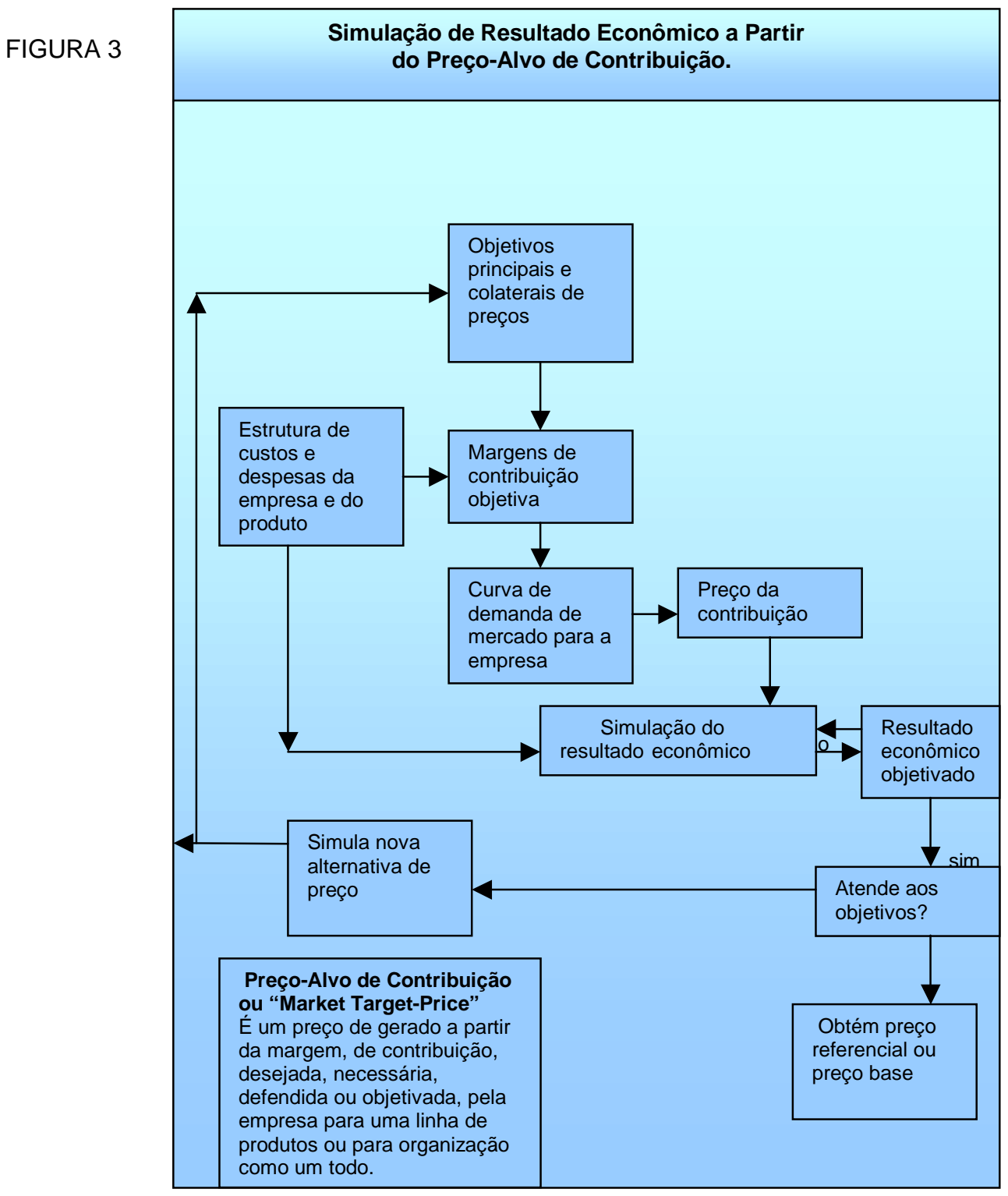

A seguir é apresentado um exemplo numérico de aplicação prática para obtenção do preçoalvo de contribuição, partindo-se do mesmo conjunto de dados hipotéticos para a empresa "Z", que fabrica e comercializa três produtos. A. B e $X$ e que necessita decidir qual o preço mais adequado para a venda ao produto "X" para o próximo período de um mês.

1) definição do resultado econômico líquido objetiva no período: $\$ 4.000$, e da margem de contribuição -alvo, para o produto ' $X$ " e para a empresa: "Todos os produtos devem gerar um índice de margem de contribuição correspondente de no mínimo $45 \%$ das receitas liquidas de vendas': 
2) projeção da estrutura de custos e despesas empresa (os mesmos dados do exemplo anterior);

3) projeção da curva de demanda do produto para a empresa,

\begin{tabular}{|c|c|c|c|}
\hline \multicolumn{2}{|c|}{ Preço de Venda } & \multirow[t]{2}{*}{ Quantidades } & $\begin{array}{c}\text { Receita } \\
\text { Bruta de vendas }\end{array}$ \\
\hline Liquido & Bruto & & \\
\hline 9,00 & 10,00 & 1.000 & 10.000 \\
\hline $12,73^{*}$ & 14,14 & 900 & 12.726 \\
\hline 18,00 & 20,00 & 800 & 16.000 \\
\hline 22,50 & 25,00 & 700 & 17.500 \\
\hline & $\begin{array}{l}\text { lvo de contrib } \\
\text { de margem de }\end{array}$ & $\begin{array}{l}\text { obtido a partir do } \\
\text { buição Objetiva }\end{array}$ & \\
\hline
\end{tabular}

* 12,73 = [7,00/(1-0,45)], ou seja, o preço-alvo de contribuição foi obtido através da divisão do custo variável operacional unitário por "um", menos o índice de margem de contribuição objetivado. O preço de vendas brutos foram obtidos a partir do percentual de dez por cento dos impostos variáveis sobre vendas.

4) projeção das vendas dos demais produtos da Empresa (os mesmos dados do exemplo anterior);

5) simulação do resultado econômico:

\begin{tabular}{|c|c|c|c|c|}
\hline \multicolumn{5}{|c|}{ Demonstração do Resultado Econômico } \\
\hline Produtos & A & B & $\mathbf{X}$ & TOTAL \\
\hline Receita Bruta de Vendas & 15.000 & 24.000 & 12,726 & 51.726 \\
\hline Impostos Variáveis sobre Vendas & 1.500 & 2.400 & 1.273 & 5.173 \\
\hline Receita Liquida de Vendas & 13.500 & 21.600 & 11.453 & 46.553 \\
\hline Custo e Despesas Variáveis Operacionais & 7.200 & 12.000 & 6.300 & 25.500 \\
\hline Margem de Contribuição & 6.300 & 9.600 & 5.153 & 21.053 \\
\hline Custos e Despesas Fixas Diretas & 2.000 & 0 & 0 & 2.000 \\
\hline Custos de Oportunidade Específicos & 150 & 0 & 0 & 150 \\
\hline Margem Direta & 4.150 & 9.600 & 5.153 & 18.903 \\
\hline Custos e Despesas Fixas Estruturais & - & - & - & 8.000 \\
\hline Custo de Oportunidade do Negócio & - & - & - & 2.000 \\
\hline Resultado Econômico antes do Imp. de Renda & - & - & - & 8.903 \\
\hline Provisão para o Imposto de Renda & - & - & - & 3.561 \\
\hline Resultado Econômico Liquido & - & - & - & 5.342 \\
\hline
\end{tabular}


Neste caso, o preço-alvo de contribuição de $\$ 14,14$ bruto é plenamente aceitável, pois o resultado econômico líquido gerado, de \$5.342. Nesta alternativa de preço é superior ao lucro objetivado. de $\$ 4.000$, pela empresa para o período, e o índice de margem de contribuição obtido pelo produto "X", de $45,0 \%[(5.153 / 11.453$ 1 1) x 100] está de acordo com o índice de margem de contribuição alvo da empresa.

No entanto, um gestor de preços atento aos movimentos de mercado, consciente do seu posicionamento da empresa nesse voltado para a otimização do resultado econômico, poderia, ao analisar a curva de demanda de mercado para o produto " $X$ " da empresa, decidir por outro nível de preço; como por exemplo, o preço bruto de venda de $\$ 25,00$ que gera um volume de vendas equivalente a 700 unidades e uma receita bruta de 3 17.500. Neste nível, o índice de margem de contribuição sobre o preço de venda líquida seria de $68,9 \%$ [(7,00/22,50) -1$) \times 100]$, portanto bem superior a 45,0\%. Utilizando os dados da simulação do resultado econômico anterior, a empresa teria um resultado econômico liquido de $\$ 8.760$.

Como produto final desta etapa, o gestor de preços obteria, independente de usar o preçoalvo de mercado ou o preço-alvo de contribuição, um preço-referencial ou um preço-base líquido de impostos e à vista, que necessitaria ser avaliado e ajustado às condições de comercialização e às políticas e diretrizes da empresa, objeto da etapa seguinte.

12. AVALIAÇÃO E ADEQUADAÇÃO DO PREÇO REFERENCIAL ÀS CONDIÇÕES DE COMERCIALIZAÇÃO

As empresas podem estabelecer diferentes preços para seus produtos, formando uma estrutura de preços coerente com suas condições de comercialização e com as políticas, diretrizes e estratégias globais e funcionais da organização e das linhas de produto. Vale ressaltar que, o preço obtido na etapa anterior é apenas um preço-referencial, ou preço-base de venda na condição à vista, liquido dos impostos e que portanto, precisa ser avaliado e ajustado. Para Kotler (1993: p. 576-81), os pontos mais relevantes que influenciam na adequação do preço são: as variações de demanda geográfica, as estratégias de descontos e concessões, os preços promocionais, os preços diferenciados e os preços com base no composto de produto.

Por último os preços também precisam ser adequados às vendas realizadas a prazo, e considerar os prazos de entrega, fazendo uso dos conceitos de equivalência de capitais, para o ajuste dos valores à vista, nas diversas condições possíveis de pagamento praticadas no mercado, levandose em conta a taxa de retorno sobre o investimento exigido pela empresa, que representa o custo de oportunidade pelo financiamento das vendas.

\section{Conclusões}

Considerando que uma das finalidades deste estudo é estruturar conceitualmente um sistema de decisões de preço de venda que incorpore as contribuições dos modelos de decisão de preço existentes, pode-se afirmar que o modelo de decisão proposto contribuí nos seguintes pontos, para melhorar o processo decisório dos gestores de preços: 
1) trata da situação decisória de preços dentro de uma abordagem sistêmica, que permite aos gestores a identificação e utilização de um fluxo lógico e normativo de dados e informações, caracterizando inclusive os produtos finais gerados em cada etapa do modelo e reconhecendo a interdependência das diversas variáveis envolvidas neste tipo de decisão;

2) fornece preços referenciais, quando adequadamente utilizado, procurando garantir a continuidade da entidade no longo prazo, através da remuneração adequada do capital investido no negócio;

3) reconhece, também sob o enfoque sistêmico, a existência e a influência dos objetivos globais da empresa sobre os objetivos de preço;

4) permite a utilização e o teste de estratégias de preço condicionadas às estratégias globais da organização;

5) é adaptável a qualquer tipo de estrutura organizacional, embora recomende que para uma gestão eficaz e eficiente de preços, deva haver uma área diretamente responsável por estas decisões;

6) incorpora também as vantagens obtidas pela utilização de um processo formal de planejamento e controle, dentro do processo de gestão. operacionalizado através de um plano orçamentário integrado;

7) atende, com razoável flexibilidade, às diversas funções-objetivos dos decisores de preços, dando possibilidades da avaliação dos resultados econômicos de cada alternativa de preço:

8) permite a simulação de resultados de cada alternativa de preços, antes da tomada de decisão final;

9) reconhece, sob a abordagem sistêmica, a influência do macroambiente da empresa nas decisões de preço;

10) reconhece a influência das diversas estruturas econômicas de mercado na formação de preços dos produtos e sua interação com a empresa;

11) leva em consideração a influência da concorrência direta e remota sobre os preços praticados pelas entidades:

12) incorpora os padrões de comportamento do consumidor derivados da lei da procura, através da quantificação da curva de demanda do produto para a empresa;

13) esclarece, interpreta e utiliza-se do inter-relacionamento entre custos, preços, volumes e lucros dentro de um ambiente empresarial caracterizado por multiprodutos e multirestrições;

14) possibilita a utilização de modelos probabilísticos para a simulação de resultados em condições de incerteza;

15) utiliza custos cientificamente predeterminados, dentro do conceito de custos-padrão, não 
permitindo com isto que ineficiências operacionais sejam repassadas aos preços;

16) permite a utilização de técnicas de pesquisa operacional, tais como a programação linear, de forma a obter a alternativa otimizadora da produção e das vendas;

17) pode ser aplicado a diferentes tipos de organizações, independente de sua natureza, ou seja, indústrias, comércio ou serviços.

Vale acrescentar, ainda, que este trabalho reconhece a importância estratégica do preço como "arma" competitiva no ambiente contemporâneo de negócios, caracterizado pela globalização dos mercados. em constantes mudanças e altamente competitivo. Assim, as empresas devem promover ações coordenadas e integradas visando o atingir sua missão e, conseqüentemente, a continuidade no longo prazo.

Resumo

Este estudo apresenta um modelo de decisão de preço de venda tendo como base um novo enfoque para o "target-price" ou "preço-alvo". Descreve e enfatiza os conceitos de preço-alvo de mercado e preço-alvo de "contribuição". Neste sentido, parte do principio de que as principais abordagens existentes de decisão de preço, orientados: pela teoria econômica, pelos custos e pelo marketing. não são satisfatórias, pois tratam o problema com parcialidade ou com ênfase excessiva em algumas variáveis criticas.

Um modelo conceitual de decisão de preços de venda, que incorpora os pontos fortes e as contribuições de cada abordagem, é proposto dentro de um contexto estratégico, sob o enfoque sistêmico e ao mesmo tempo, buscando superar as limitações de aplicabilidade dos modelos existentes.

\section{Referências Bibliográficas}

ALPERT. Mark I. Pricing Decisions. S/l: Glenview, Scott Foreman and Company, 1971.

AMA, American Management Association. Pricing: The Critical Decision. New York: Marketing Division, 1961.

BRUEGELMANN, Thomas M. et alli. How Variable Costing is Used in Pricing Decisions. Management Accounting, April 1985.

COBRA. Marcos. Administração de Marketing. São Paulo: Atlas, 1990.

DOPUCH. Nicholas, BIRNBERG. Jacob G. \& DEMSKI, Joel. Cost Accounting: Accounting Data for Management's Decisions. 2. ed. New York: Harcourt Brace Jovanovich, 1974.

HORNGREN. Charles T. \& FOSTOR. George. Cost accounting: a Managerial Emphasis $7^{\text {th }}$ ed. New Jersey: Prentice Hall, 1991.

KAPLAN. Robert S. \& ATKINSON. Anthony A.. Advanced Management Accounting. 2. ed., New Jersey: Prentice Hall. 1989

KOTLER, Philip. Administração de Marketing: Analise. planejamento. Implementação e Controle. 3. ao. São Paulo. Atlas, 1993.

MARTINS, Eliseu. Contabilidade de Custos. 5. ad. São Paulo: Atlas, 1990.

MITCHELL. Joan E. Price Determination and Price Policy. London: Allen. 1978.

MORRIS. Michael H. \& MORRIS, Gene. Política de Preços em um Mercado Competitivo e Inflacionado. São Paulo: Makron 
Books. 1994.

NAGLE, Thomas T. The Strategy and Tactics of Pricing. New Jersey: Prentice Hall, 1987.

NATIONAL ASSOCIATION OF ACOUNTANTS - NAA BULLETIN. Direct Costs are Better for Pricing. New York: Wilmer, abril, 1960.

NATIONAL ASSOCIATION Of ACGOUNTANTS - NAA BULLETIN. Flexible Costs for Pricing Decisions. New York: BACKER. Morton. maio 1961.

NATIONAL ASSOCIATION OF ACCOUNTANTS - NAA, Research Report n. 24. Product Costs for Pricing Purposes. New York. agosto. 1953.

OXENFELDT, Alfred R. Pricing for Marketing Executives. San Francisco: Wadsworth. 1961.

PINDYCK, Robert S. \& RUBINFELD, Daniel L.. Microeconômia. São Paulo: Makron Books, 1994.

PORTER. Michael E. Estratégia Competitiva: Técnicas para Análise de Indústrias e da Concorrência. Rio de Janeiro: Campus. 1986.

SAMUELSON, Paul A. Introdução à Análise Econômica. 8. ed., 2v., Rio de Janeiro: Agir. 1975.

SANTOS. Roberto Vatan dos. Modelos de Decisão para Gestão de Preço de Venda. São Paulo: 1995. Dissertação ce Mestrado. FEA/USP

STANTON. William J. Fundamentos de Marketing. 2. v.. São Paulo: Pioneira, 1980.

VASCONCELlOS FILHO. Paulo de \& Machado, Antonio de Matos Vieira (org.). Planejamento Estratégico: Formulação, Implementação e Controle. Rio de Janeiro:Livros Técnicos e Científicos: Belo Horizonte:Fundação João Pinheiro. 1979. 